\title{
AS ORIGENS DE GAIA E QUESTÕES DE IDENTIDADE. ARQUEOLOGIA E EPIGRAFIA DOS TURDULI VETERES
}

\author{
ARMANDO COELHO FERREIRA DA SILVA ${ }^{(1)}$
}

Resumo:

Reconsideração dos dados da investigação arqueológica em relação com o registo epigráfico dos pactos de hospitalidade dos Turduli Veteres, encontrados no Castro da Senhora da Saúde ou Monte Murado (Pedroso), Vila Nova de Gaia, Portugal, equacionando o contributo das migrações internas, mencionadas nas fontes clássicas, para a formação da identidade regional.

Palavras-Chave: Gaia, Migrações, Túrdulos, Identidade.

The origins of Gaia and issues of identity. The archaeology and epigraphy of Turduli Veteres
Reconsideration of the archaeological data in relation to the epigraphic record from hospitality pacts of Turduli
Veteres found in Castro da Senhora da Saúde or Monte Murado (Pedroso), Vila Nova de Gaia, Portugal,
equating the contribution of internal migrations, mentioned in classical sources, to the formation of regional
identity.

Keywords: Gaia, Migrations, Turduli, Identity.

Received: 18 November 2015; Accepted: 12 December 2015

Para o Professor Doutor Humberto Baquero Moreno,

com especial memória da amizade cimentada no Gabinete de História e Arqueologia de Vila Nova de Gaia.

Um dos dados mais relevantes da nossa investigação sobre o povoamento antigo do noroeste de Portugal consistiu sem dúvida na evidência epigráfica que obtivemos sobre a ocupação da margem esquerda do curso terminal do rio Douro por uma entidade étnica apelidada de Turduli Veteres (SILVA 1983, 1994, 2007: 632-633, Epig. 46-47), confirmando literalmente as referências da Chorographia de P. Mela e sobretudo da Naturalis Historia de C. Plinius, relacionáveis com uma celebrada passagem da Geographia de Estrabão sobre a travessia do "rio do esquecimento", de que resultaria a ocupação de comunidades célticas em torno da atual Corunha e túrdulas na margem sul do Douro litoral (SCHULTEN 1935, 1937).

Com efeito, segundo Estrabão (3. 3. 4-5), viviam junto do cabo Nérion (Finisterra) uns célticos (Kéltikoi), aparentados aos das margens do Anas (Guadiana), que para aí se teriam dirigido na sequência de uma expedição conjunta com túrdulos. "E dizem - acrescenta Estrabão - que, passado o rio Lima, os túrdulos desertaram", separando-se dos seus companheiros, após luta travada entre si. Tendo perecido o seu chefe, os túrdulos ficaram sem guia para regressar e, "esquecidos" do caminho da sua antiga pátria, dispersaram-se pela região. Encontra Estrabão nesta circunstância a explicação para o nome desse rio, com correspondência ao Léthes, traduzido em latim por Oblivio, "Olvido", "Esquecimento", designação com que o rio Limaía, "Lima", é cognominada pelos autores latinos.

P. Mela e C. Plínio situam igualmente a presença de povos célticos na área setentrional, e a eles se reportam também diversos registos epigráficos, apontando P. Mela $(3,8)$ a presença de turduli et turdulorum oppida, "túrdulos e cidades dos túrdulos", entre os rios Tejo e Douro, e precisando C. Plínio (4, 112-113) a sua localização, dizendo que o rio Douro separava os calaicos dos lusitanos, de um lado brácaros e do outro túrdulos. E especifica mesmo que a partir do Douro começava a Lusitânia, onde habitavam os turduli veteres, de que reiteramos a relevância da sua confirmação epigráfica (Figs. 1 e 2).

Consensualizado o palco desta migração, com origem na Betúria, para o noroeste, pela maior parte dos autores que se dedicaram ao seu estudo, permanece questionável a cronologia dos diversos cenários propostos face à caracterização da ocupação proto-histórica do noroeste peninsular ao longo do I milénio a. C., de que se apontam, em especial, os seguintes: meados do I milénio a. C., na sequência do domínio cartaginês no Mediterrâneo ocidental; $2^{\mathrm{a}}$ metade do século III a. C., com a pressão púnica e celtibérica no sudoeste peninsular; contexto das guerras lusitanas, em meados do século II a. C.

${ }^{(1)}$ Professor catedrático jubilado da Faculdade de Letras da Universidade do Porto; Investigador do CITCEM - Centro de Investigação Transdisciplinar Cultura, Espaço e Memória, FLUP/FCT. Email: acfsilva@sapo.pt 


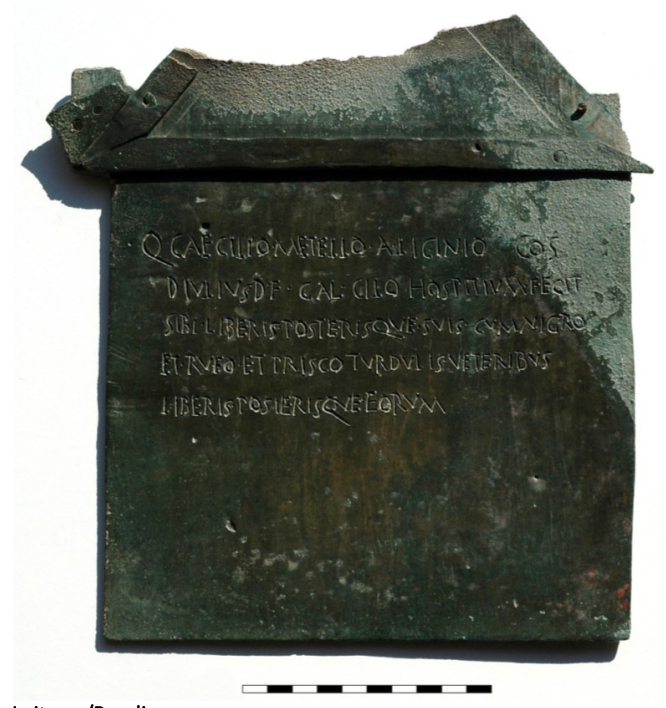

Leitura /Reading:

Q(uinto) Caecilio Metello A(ulo) Licinio co(n)s(ulibus)

D(ecimus) Iulius D(ecimi) f(ilius) Gal(eria tribu) Cilo hospitium fecit

sibi liberis posterisque suis cum Nigro

et Rufo et Prisco Turdulis Veteribus

liberis posterisque eorum.

Fig. 1. Tessera hospitalis 1 (ano 7 d.C.). (Foto: José Vigário. Solar Condes de Resende, Câmara Municipal de Vila Nova de Gaia).

Fig. 1. Tessera hospitalis 1 (7 A.D.). (Foto: José Vigário. Solar Condes de Resende, Câmara Municipal de Vila Nova de Gaia).

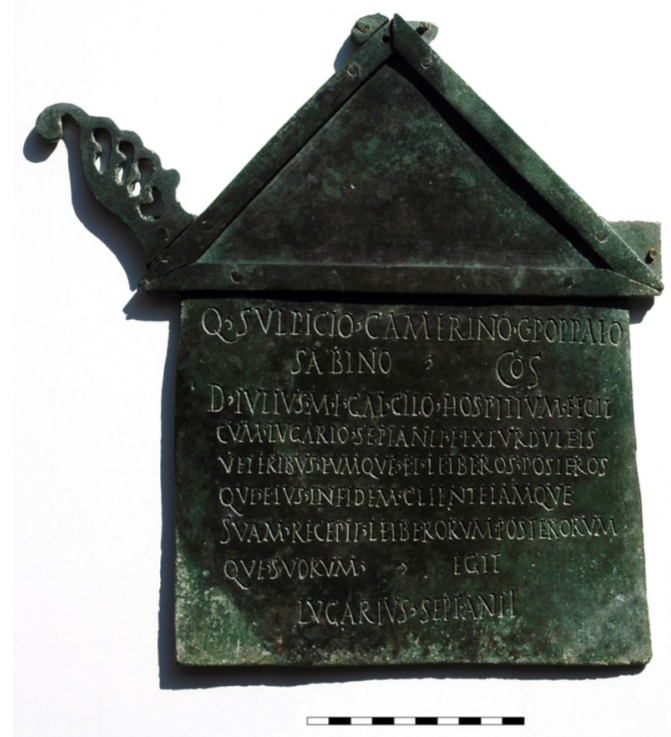

Leitura/ Reading:

Q(uinto) Sulpicio Camerino C(aio) Poppaeo

Sabino co(n)s(ulibus)

D(ecimus) Iulius M(arci) f(ilius) Gal(eria tribu) Cilo hospitium fecit cum Lugario Septanii f(ilio) ex Turduleis

Veteribus eumque recepit leiberorum posterorum que suorum egit

Lugarius Septanii.

Fig. 2 Tessera hospitalis 2 (ano 9 d.C.).(Foto: José Vigário. Solar Condes de Resende, Câmara Municipal de Vila Nova de Gaia).

Fig. 2 Tessera hospitalis 2 (9 A.D.). (Foto: José Vigário. Solar Condes de Resende, Câmara Municipal de Vila Nova de Gaia).
Ao situar estes acontecimentos em momento pouco anterior a Possidónio, como fonte da informação recolhida por Estrabão, e que teria a ver com as convulsões relacionadas com as guerras de Roma contra celtiberos e lusitanos, foi esta datação, mais tardia, que associou estas movimentações com as campanhas de Décimo Júnio Bruto, tornando-se em opinião mais vulgarizada desde o interessante estudo de A. García y Bellido (1951: 490-496) (Fig. 3), sobre as "pequenas invasões" e as "transmigrações" internas, a propósito da problemática das invasões indo-europeias na Hispânia.

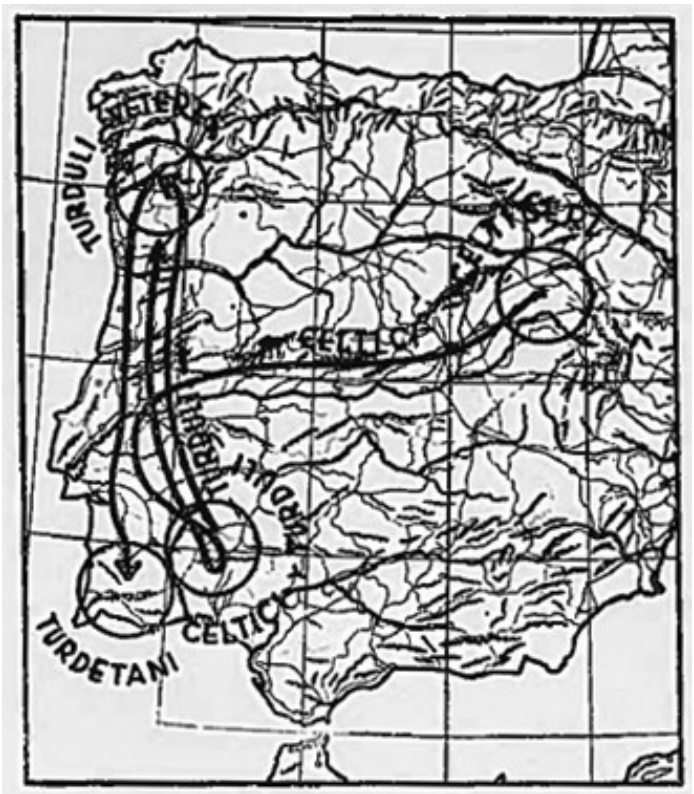

Fig. 3. Migrações de Túrdulos e Célticos (García y Bellido 1951).

Fig. 3. Turduli and Celtic migrations (García y Bellido 1951).

Foi justamente o enquadramento deste episódio no contexto das guerras lusitanas, em meados do século II a.C., recentemente retomado por J. C. Olivares Pedreño (2013), que propõe o seu ajustamento no quadro das campanhas do proconsulado de Fábio Máximo Serviliano em torno de 141-140 a. C., continuadas por Servílio Cipião e Décimo Júnio Bruto, de acordo com os acontecimentos político-militares narrados pelas fontes literárias e os dados do registo arqueológico, tanto da Betúria, como do noroeste peninsular. $\mathrm{O}$ impacto da passagem do rio do "Esquecimento", que se reflete nas fontes, a propósito da expedição de Décimo Júnio Bruto, justificará, segundo Olivares Pedreño, a sua aproximação da memória do episódio da migração céltico-túrdula.

Outras propostas sugerem a sua identificação com deslocações, datadas ainda mais tardiamente, de grupos para o noroeste, que teriam tido em torno dos meados do século I a.C., se não mesmo já durante a época augústea, por motivo da exploração aurífera na região (SALINAS DE FRÍAS 2011) ou como auxiliares das legiões romanas (JORDÁ CERDÁ 
1984: 8-9). Neste sentido converge a hipótese formulada por J. Cardim Ribeiro, e do agrado de A. Guerra (1998: 856), ao interpretar o adjetivo veteres com conotação militar, equivalente à designação de veterani, com significado de "experimentados", que identificaria essa entidade étnica com elementos hispânicos integrados no exército romano, recrutados em território meridional, que se teriam fixado naquelas paragens, após a desmobilização.

Mas, já J. Alarcão (1992: 344) sugerira maior antiguidade para esta migração, situando-a na segunda metade do século III a.C., como consequência da pressão exercida por cartagineses e celtiberos no sudoeste peninsular, segundo opinião de que se aproxima L. Berrocal-Rangel (1998: 26), que a tinha como incompreensível em contextos do século I a.C.

Por nossa parte, vimos insistindo desde há muito (SILVA 1983, 1986, 2007) na hipótese da grande antiguidade desta migração com base em argumentos transdisciplinares, sobretudo de natureza arqueológica, linguística e da antropologia cultural, que havemos por bem sintetizar:

1. Os contornos da narrativa estraboniana, melhor dizendo, de Possidónio-Estrabão, como nota A. García Bellido (1951: 493), aparecem, a nosso ver, logo de imediato, com uma referência verbal, fasí, "dizem", adequada à transmissão de um discurso mitológico de algo que aconteceu in illo tempore, "naquele tempo", em data imemorial, conforme se postula para tal categorização. Para esta delimitação concorre o entendimento do mito como património imaterial indígena preexistente à migração céltico-túrdula (GARCÍA QUINTELA 1986) e o significado inerente ao nome do rio (WITCZAK 2003), explicáveis segundo a ideologia e a linguística indo -europeia bem assimilada no mundo céltico.

2. Como mencionámos atrás, o adjetivo Veteres tem sido merecedor de variada significação conforme a diversidade dos autores. Não nos parecendo poder compaginar-se a sugestão de tal veterania com qualquer relação à ordem militar ou económica romanas, tal designação faz transparecer abertamente que se deva tratar de uma deslocação anterior a outras que poderão ser referenciáveis pelo nome comum de túrdulos.

3. Servimo-nos como apoio deste relacionamento, conforme explicitado noutra circunstância (Silva \& PINTO 2012), dos dados estratigráficos das nossas escavações no Castro de Romariz, Santa Maria da Feira, cujos níveis de ocupação mais antigos revelam ocupação com anterioridade aos meados do $1^{\circ}$ milénio a. C., com origens no final da Idade do Bronze e sequente relacionamento com o horizonte orientalizante durante os séculos VII/ VI a. C., que se tornou notoriamente crescente após o termo do reino de Tartessos, na sequência do domínio cartaginês no Mediterrâneo ocidental.

Para este ponto de referência convergem as indicações do numeroso espólio de cerâmica indígena micácea e de fabrico manual associada a um significativo conjunto de produtos de importação de procedência e/ou tradição púnica com que concordará a datação de $600 \pm 100$ a. C. obtida por C14 (UGRA 203) que, associada ao resultado de de $520 \pm 100$ obtido de outra amostra (CSIC 83) do Castro de Borneiro, na Corunha, também poderá sugerir a cronologia desta ocorrência em torno dos meados do I milénio a. C., para o que se poderá contar com o apoio de outras datações absolutas para a região (SILVA 2007: 41).

As alterações do registo arqueológico que transparecem destas observações não têm confronto com todas as outras que se verificaram na noroeste, nomeadamente as que tiveram lugar na sequência da campanha de Décimo Júnio Bruto, de primordial importância para a reorganização interna do território, mas sem reflexos exógenos na cultura material.

Nestes termos, mais nos aproximamos dos pontos de vista de M. Almagro-Gorbea e M. Torres Ortiz (2009) (Fig. 4) sobre a colonização tartéssia atlântica por via marítima até ao estuário do Tejo, e que, depois desta zona, contaria com o estabelecimento de feitorias secundárias até ao Douro e, provavelmente, até à Galiza, com o fím de controlar as rotas comerciais do estanho e do ouro. Neste processo, caberá porventura interpretar o lugar de Gaia em relação com o controle da foz do Douro e a presença dos Turduli Veteres testemunhada pelas tesserae hospitales achadas no Monte Murado, que confirmam que este povo ainda mantinha a sua consciência étnica nos inícios do século I d.C. (Figs. 1, 2, 5 a 8).

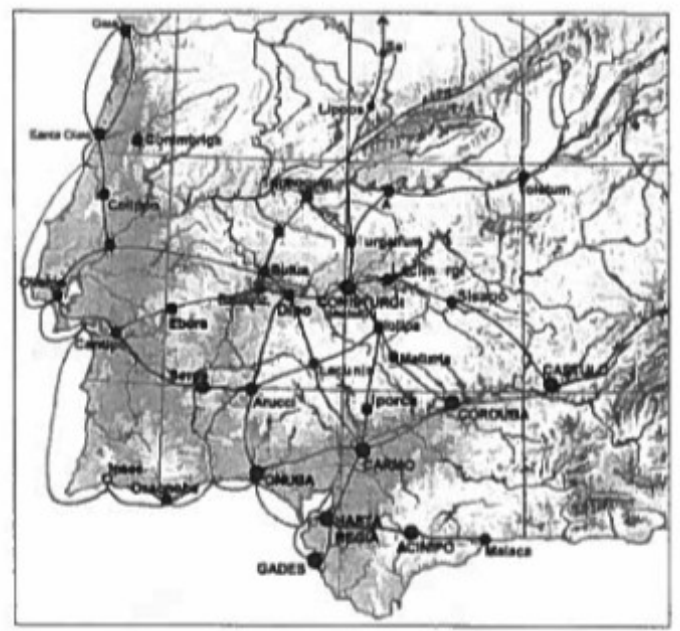

Fig. 4. Rede de ligações do sudoeste penisular no período orientalizante (ALMAGRO-GORBEA \& TORRES 2009).

Fig. 4. Contact network in Southwestern Iberia during the Orientalising period (ALMAGRO-GORBEA \& TORRES 2009). 


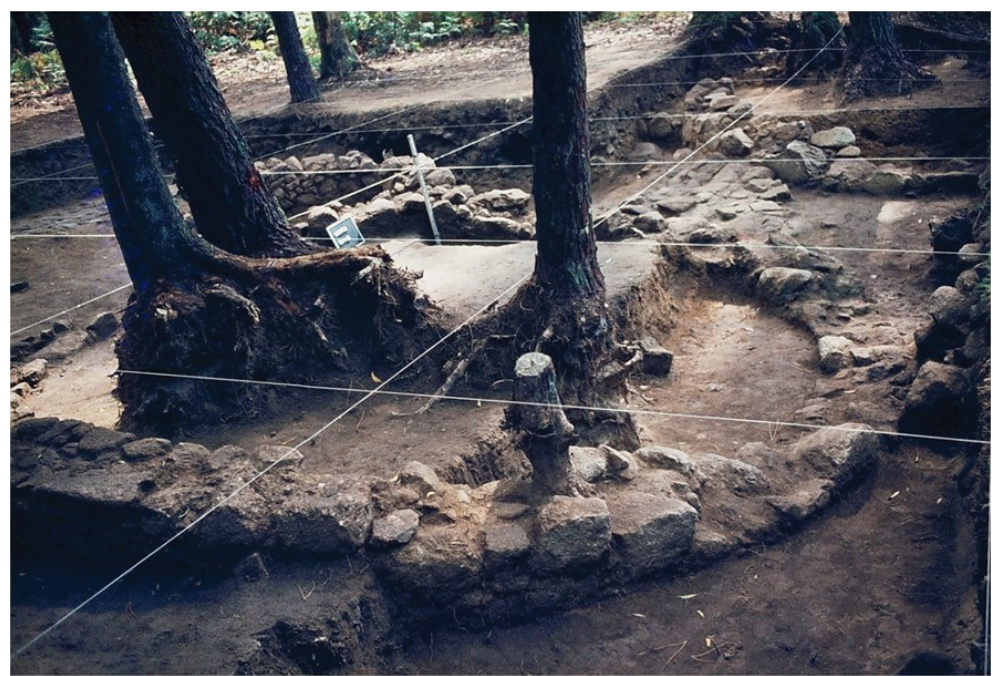

Fig. 5. Monte Murado (Pedroso, Vila Nova de Gaia) - Escavações arqueológicas de 1983. Fig. 5. Monte Murado (Pedroso, Vila Nova de Gaia) - The 1983 archaeological excavation.

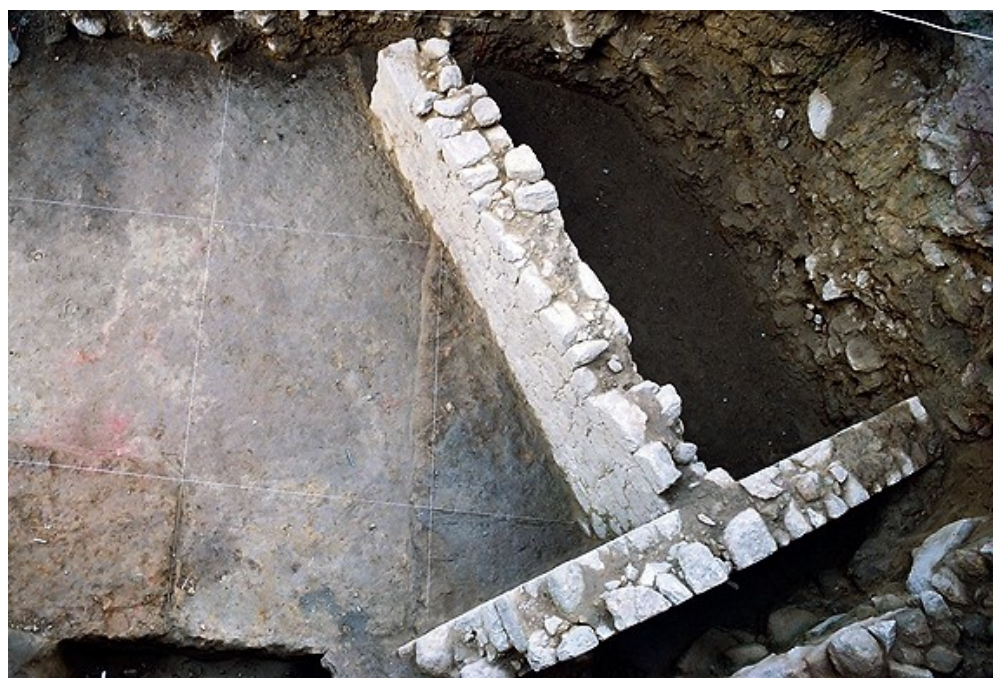

Fig. 6. Monte Murado (Pedroso, Vila Nova de Gaia) - Casa de Decimus Iulius Cilo. Fig. 6. Monte Murado (Pedroso, Vila Nova de Gaia) - The house of Decimus Iulius Cilo.

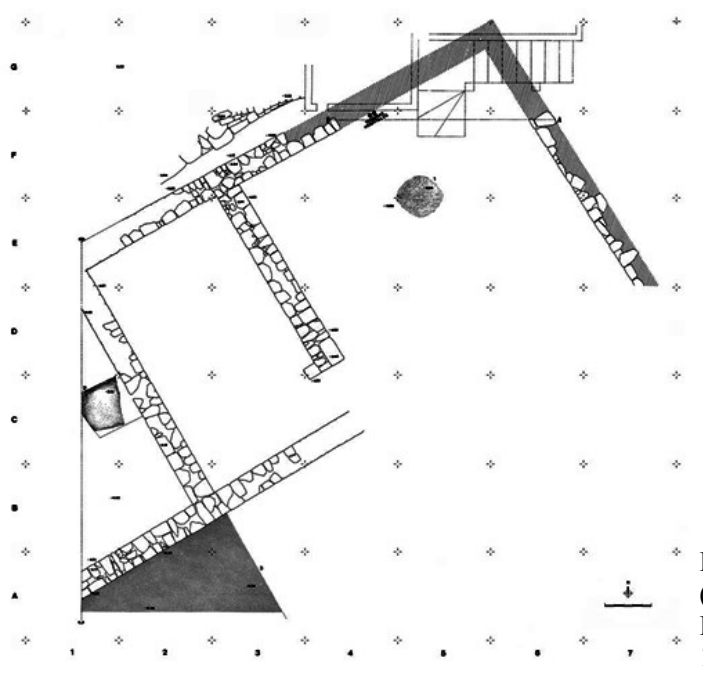

Fig. 7. Monte Murado - Casa de Decimus Julius Cilo (Escavações arqueológicas de 1983: Planta).

Fig. 7. Monte Murado - The house of Decimus Julius Cilo (the 1983 archaeological excavation: the house plan). 


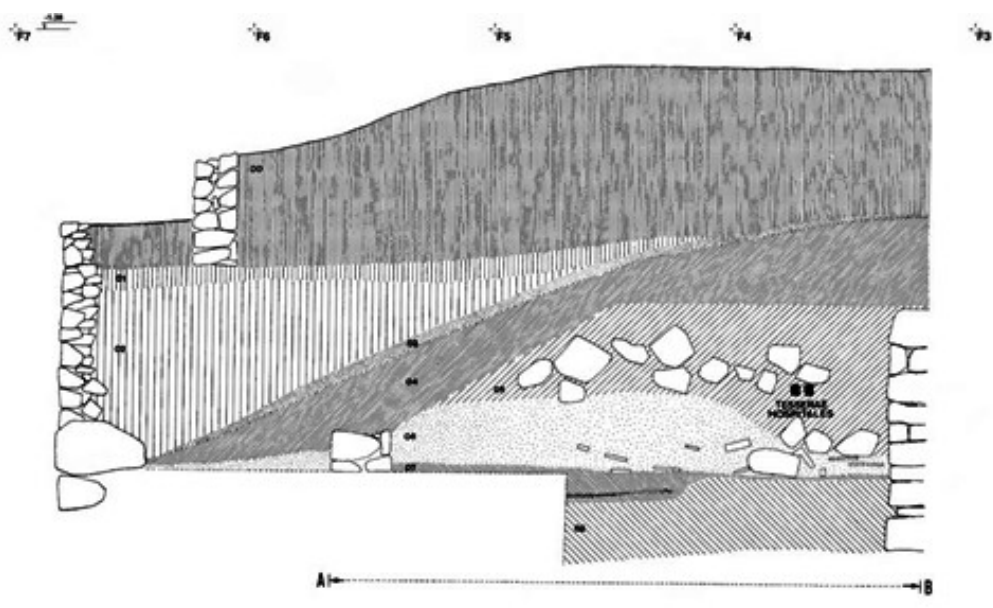

Fig. 8. Monte Murado - Casa de Decimus Julius Cilo (Escavações arqueológicas de 1983: Corte estratigráfico).

Fig. 8. Monte Murado - The house of Decimus Julius Cilo (the 1983 archaeological excavation: cross-section).

A este contexto se reportará a hipótese anteriormente avançada por V. Mantas (1996: 650), seguindo, de resto, uma proposta de E. Hübner (1881: 67-68) de identificar a designação de Caeno oppidum como atribuível ao Castelo de Gaia, cuja ocupação pré-romana deste povoado fortificado, frente a Cale, é confirmada por documentação arqueológica, das nossas escavações (SILVA 1984) (Fig. 9) e de diversas intervenções posteriores (SILVA \& PINTO 2012).

Ocorre este topónimo uma única vez nas fontes clássicas, na Cosmografia do Anónimo de Ravena (SCHNETZ 1940: 307.4), que consiste numa compilação de itinerários romanos no século VII, datável entre 638-678, baseada em documentação anterior dos séculos III-IV, designadamente a Tabula de Peutinger (MILlERI 1887), que, tendo perdido a parte referente à Península Ibérica, foi justamente reconstituída com base na Cosmografia do Anónimo de Ravena (Fig. 10).

Atendendo às inúmeras corruptelas e variantes, devidas aos seus copistas ulteriores, e à onomástica pré-romana da Lusitânia, em que se verifica uma presença do antropónimo Caeno, entre as versões linguísticas possíveis para a forma latinizada do termo grego, entendemos optar por esta versão de preferência a Ceno oppido, como chegou até nós.

E, mais julgamos, assim, com Vasco Mantas (1996: 650) que, de acordo com os testemunhos conhecidos, a identificação do Castelo de Gaia com Caeno oppidum, situado entre Langobriga e Calo, é francamente possível, estando, porventura, na origem do topónimo Gaia, que poderá ter eventualmente derivado de uma forma, reconstruída, como a de Cania < Caena (civitas).

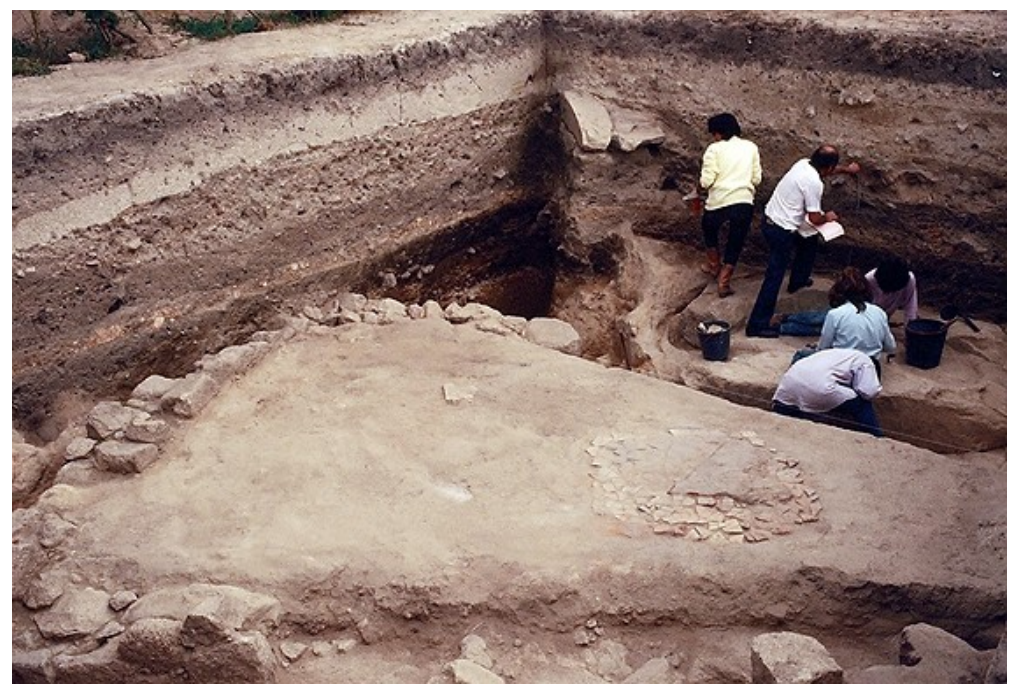

Fig. 9. Castelo de Gaia - Escavações arqueológicas de 1985.

Fig. 9. Castelo de Gaia - The 1985 archaeological excavation. 


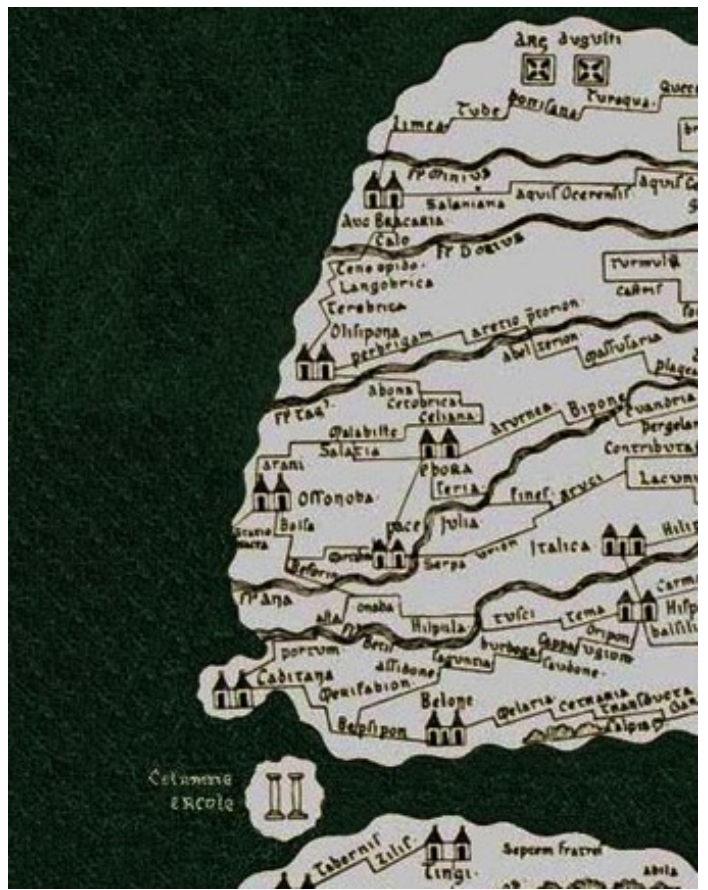

Fig. 10. Tabula de Peutinger

(http://metrhispanic.com/tag/1000-km/ ).

Fig. 10. Peutinger's Tabula

(http://metrhispanic.com/tag/1000-km/).

A proximidade etimológica deste vocábulo com Can- / Con- com eventual interpretação de natureza totémica, relacionada com a significação de canis lupus ("Cão/Lobo") sugere tratar-se de referência identitária coberta pelo étnico maior alcançado pela designação de Turduli Veteres, que se tornou extensiva a toda a região das futuras terras medievais de Santa Maria. A frequência de topónimos, como Canidelo, Canedo, Coimbrões, no seu âmbito geográfico mais restrito, a que poderá acrescer a presença de versões toponímicas deste vocábulo, como Lobão e Corga do Lobão, nas imediações do Castro de Romariz, ajustam-se à sugestão do referido radical com o limite setentrional da colonização da costa atlântica por parte de entidades étnicas meridionais, designados como Cónios, e variantes, desde as fontes clássicas mais antigas, como a Ora Maritima de Avieno.

E, como observou A. Guerra (1998: 839), talvez se deva admitir a assimilação destes Cónios com os Túrdulos=Turdetanos, se, como tal, ponderarmos a sua presença nessa região, tal como foi referenciada na Geografia de Ptolomeu (5.4), e a quem convirá com propriedade a adjetivação de Veteres, por se tratar do núcleo de túrdulos reconhecido como mais antigo. Com advento datável pelo século VII a.C., a eles se terão juntado, por meados do milénio, os parentes, perdidos, da expedição estraboniana, com eles se promovendo um processo de etnogénese que percorrerá o restante tempo do $1^{\circ}$ milénio a.C., conferindo ao questionamento identitário das origens de Gaia uma ances- tralidade mítica, porventura, pervivente na lenda do rei Ramiro ou Lenda de Gaia enquanto interpretatio das relações estabelecidas entre as chefaturas indígenas e essas comunidades meridionais portadoras de bens de prestígio quantas vezes intermediados por via de casamentos ou outras uniões de facto.

\section{BIBLIOGRAFIA}

AlARCÃO, J. 1992. Etnogeografia da fachada atlântica ocidental da Península Ibérica. In: Paleoetnología de la Península Ibérica. Actas de la Reunión celebrada en la Facultad de Geografía y Historia de la Universidad Complutense (Madrid, 13-15 Diciembre de 1989). Complutum, Vol. 2/3: 339-346.

Almagro-Gorbea, M. \& Torres Ortíz, M. 2009. La colonización de la costa atlântica de Portugal: Fenícios ou Tartéssicos? In: Acta Palaeohispanica X. Actas do X Coloquio Internacional sobre Línguas e Culturas Paleo-hispánicas (Lisboa, 26-28 de Fevereiro de 2009), Palaeohispanica, 9: 113-142.

BerRoCAl-RANGel, L. 1998. La Baeturia. Un território prerromano en la Baja Extremadura. Badajoz, Diputación de Badajoz.

GARcía Quintela, M.V. 1986. El río del olvido (variaciones en torno a un episodio de la conquista de Hispania). In: J.C. BERMEJO (Ed.), Mitología y mitos da la Hispania preromana 2, Madrid, Akal: 75-86.

GARCíA Y BELlido, A. 1951. Algunos problemas relativos a las invasiones indoeuropeas en España: Pequeñas invasiones y transmigraciones internas. Archivo Español de Arqueología, 23 (82): 490-496.

GUERRA, A. 1998. Nomes pré-romanos de povos e lugares do ocidente peninsular. Lisboa, Faculdade de Letras da Universidade de Lisboa (Diss. Doutoramento, policop.).

HÜBNER, E. 1881. Notícias archeologicas de Portugal. Lisboa, Typographia da Academia.

JORDÁ CERDÁ, F. 1984. Notas sobre la cultura castreña del noroeste peninsular. Memorias de Historia Antigua, 6: 7-14.

MANTAS, V.G. 1996. A rede viária romana da faixa atlântica entre Lisboa e Braga. Coimbra, Faculdade de Letras da Universidade de Coimbra (Diss. Doutoramento, policop.)

Milleri, C. (Ed.) 1887. Tabula Peutingeriana, Segmentum I. Spania et Mauritania (PDF v.6-640 KB).

Olivares Pedreño, J.C. 2013. La migración de los Célticos y Turdulos de la Beturia hacia el noroeste de Hispania, Cuaderno de Estudios Gallegos, 60 (126): 5184.

SALINAS DE FríAS, M. 2011. Las fuentes clássicas y el poblamiento prerromano del occidente peninsular. In: R. Ruíz Zapatero \& J. Álvarez-Sanchís (Ed.), Castros y verracos. Las gentes de la Edad del Hierro en el occidente de Iberia. Ávila, Institución Gran Duque de Alba, Diputación de Ávila: 129-158.

SCHNETZ, J. (Ed.) 1940. Ravennatis Anonymi Cosmographia et Guidonis Geographica. Itineraria Romana, II. Lipsia. 
Schulten, A. 1935. Fontes Hispaniae Antiquae III. Las guerras de 237 - 154 a. de J.C. Barcelona, Universidad de Barcelona.

Schulten, A. 1937. Fontes Hispaniae Antiquae IV. Las guerras de $154-72$ a. de J.C. Barcelona, Universidad de Barcelona.

SiLVA, A.C.F. 1983. As tesserae hospitales do Castro de Senhora de Saúde ou Monte Murado (Pedroso, V. N. Gaia). Contributo para o estudio das institucões e do povoamento da Hispânia Antiga. Gaya, 1: 9-26.

SILVA, A.C.F. 1984. Aspectos da proto-história e romanização do concelho de Vila Nova de Gaia e problemática do seu povoamento. Gaya, 2: 39-58.

SiLvA, A.C.F. 1986. A cultura castreja no noroeste de Portugal. Paços de Ferreira, Câmara Municipal de Paços de Ferreira e Museu Arqueológico da Citania de Sanfins.

SilvA, A.C.F. 1994. Origens do Porto. In: L.A. Oliveira Ramos (Dir.) História do Porto, Porto, Porto Editora: 44-117.

SiLVA, A.C.F. 2007. A cultura castreja no noroeste de Portugal. $2^{\mathrm{a}}$ ed., Paços de Ferreira, Câmara Municipal de Paços de Ferreira, Museu Arqueológico da Citânia de Sanfins e Centro de Arqueología Castreja e Estudos Célticos.

SiLVA, A.C.F. \& PINTO, F.M.S. 2012. O Castro de Romariz e a Proto-história entre Douro e Vouga. Villa da Feira - Terra de Santa Maria, 31: 11-62.

WiTCZAK, K.T. 2003. El río del Olvido. Veleia, 20: 355-359. 